\title{
An Extended Model of Currency Options Applicable as Policy Tool for Central Banks with Inflation Targeting and Dollarized Economies
}

\author{
Luis-Felipe Arizmendi ${ }^{1,2}$ \\ ${ }^{1}$ GPI Asset Management S.A., Lima, Perú \\ ${ }^{2}$ Center for International Policy Studies, Department of Economics, Fordham University, New York, USA \\ Email: farizmendi@gpiam.com
}

Received March 5, 2013; revised April 15, 2013; accepted May 15, 2013

Copyright (C) 2013 Luis-Felipe Arizmendi. This is an open access article distributed under the Creative Commons Attribution License, which permits unrestricted use, distribution, and reproduction in any medium, provided the original work is properly cited.

\begin{abstract}
The purpose of this paper is to provide a new set of tools for policy makers at central banks. Based on the GarmanKohlhagen [1] formula for currency options, this research extends it with the Taylor-rule expression used for inflation targeting, thus obtaining the corresponding Call and Put options and the first and higher-degree partial derivatives known as "Greeks" for key variables such as the policy target domestic interest rate and the output gap.
\end{abstract}

Keywords: Inflation Targeting; Central Bank Policies; Exchange Rates; Currency Options

\section{Introduction}

In spite of the very recent debate in Caballero [2], Good friend [3], Taylor [4,5] and Woodford [6], on some limitations on how to apply it, the well-known Taylor-rule for inflation targeting (IT) has to be recognized as one of the most fruitful tools provided by macroeconomists to facilitate predictability and credibility related to changes in future price level. It is also claimed that for IT to be successful is required to include a high degree of exchange rate flexibility as in Ostry, Ghosh and Chamon [7]. In today's world, emerging markets economists and policy makers are no longer engaged in just choosing an exchange rate regime as a framework for the economic activity in a country, but rather to optimize growth, employment and private investment. In that sense, the adoption of the Taylor-rule for IT has become not only fashionable but also useful to relate the effects in the nominal interest rate with the desired and observed levels of inflation, changes in the Real GDP and the short-term trends in the business cycle, as seen in Apergis, Miller, Panethimitakis and Vamvakidis [8], and Salvatore [9,10].

There are, however, some potential long-term weaknesses and yet unresolved policy issues when applying IT to dollarized economies. Ozsoz, Rengifo and Salvatore [11] show additional challenges for the policy-makers that come from the dollarization phenomena and the potential currency competition. It brings complex situations, where the effectiveness of the monetary policy may appear partially or temporarily restricted, opening the case for increasing imbalances that may precipitate financial crises in the medium-term, with massive inflows of foreign speculative capital and abrupt local currency appreciation.

The use of market-related tools, such as currency options, is not strange to literature (see Veestraeten [12]), although they have been just partially employed in a few countries, and none has attempted to merge currency option models, such as the Garman-Kohlhagen [1], within an IT framework.

There are some cases that will help us to set the boundaries of this proposed research. As seen in works of Archer [13], Bernedo and Azañero [14], Breuer [15], Gürsu and Öncü [16], Mandeng [17], Orellana and Rodriguez [18], Suk and Malliaris [19], Taylor [20], and Uribe and Toro [21], there is some recent evidence to assume that exchange rate intervention by employing market-friendly tools such as currency options, can provide the additional instruments many central banks in small dollarized openeconomies, are looking for.

\section{The Model}

We will employ the model presented by Taylor [22], Molodtsova and Papell [23], where the most widely used expression by central banks is usually written as: 


$$
i_{t}=\pi_{t}+\varphi\left(\pi_{t}-\bar{\pi}\right)+\gamma Y_{t}+R
$$

where $i_{t}$ is the policy target domestic interest rate, $\pi_{t}$ is the actual inflation rate, $\bar{\pi}$ is the target inflation rate, $Y_{t}$ is the Output gap (potential vs actual real GDP), and $R$ is the equilibrium real interest rate.

Rearranging some terms to obtain a form easier to compute, we get:

$$
i_{t}-\pi_{t}=R+\varphi \pi_{t}-\varphi \bar{\pi}+\gamma Y_{t}
$$

by separating in two terms, we get:

$$
i_{t}=k_{t}+m
$$

where $k_{t}=(1+\varphi) \pi_{t}+\gamma Y_{t}$,

and $m=R-\varphi \bar{\pi}$

As a suggestion to avoid multicollinearity, the regressional form may be set as:

$$
\left(i_{t}-\pi_{t}\right)=R+\varphi\left(\pi_{t}-\bar{\pi}\right)+\gamma Y_{t}+\varepsilon_{t}
$$

After obtaining the fitted values for $i_{t}-\pi_{t}$, and then substracting $\pi_{t}$, we obtain $\hat{i}_{t}$ as the estimated target nominal interest rate.

Renaming the terms and using $T$ (for Taylor) instead of $t$ for the purpose to identify them as instrumental values that come from the Taylor expression, the estimated regression can be written as:

$$
\hat{i}_{T}=\hat{k}_{T}+\hat{m} .
$$

Whereas, by grouping terms from (1.a.1), we get:

$$
\begin{gathered}
\hat{k}_{T}=(1+\varphi) \pi_{T}+\gamma Y_{T}+\varepsilon_{T} \\
\hat{m}=\hat{R}-\varphi \bar{\pi}
\end{gathered}
$$

Being the Garman-Kohlhagen (GK) model an European option, with $q$ being the risk-free foreign interest rate, and $\Phi(d)$, the cumulative distribution function for the standard normal distribution, the values $d_{1}$ and $d_{2}$ of the GK formula with the coefficients from the Taylorrule, the modified $d_{1}^{T}$ and $d_{2}^{T}$ are:

$$
d_{1}^{T}=\frac{\log (S / X)+\left(\hat{k}_{T}+\hat{m}-q+\left(\frac{\sigma^{2}}{2}\right)\right) t}{\sigma \sqrt{t}}
$$

and,

$$
d_{2}^{T}=d_{1}^{T}-\sigma \sqrt{t}
$$

So, the expressions for the Call and the Put options of the GK-Taylor modified will be:

$$
\begin{gathered}
C=S \mathrm{e}^{-q t} \Phi\left(d_{1}^{T}\right)-X \mathrm{e}^{-\left(\hat{k}_{T}+\hat{m}\right) t} \Phi\left(d_{2}^{T}\right) \\
P=X \mathrm{e}^{-\left(\hat{k}_{T}+\hat{m}\right) t} \Phi\left(-d_{2}^{T}\right)-S \mathrm{e}^{-q t} \Phi\left(-d_{1}^{T}\right)
\end{gathered}
$$

Being log the natural logarithm, and:
$S=$ the current exchange rate (domestic currency per unit of foreign currency);

$X=$ the strike exchange rate;

$\hat{k}_{T}+\hat{m}=$ the estimated domestic target interest rate

$\left(\hat{i}_{T}\right)$ by the Taylor-rule regression;

$q=$ the continuously compounded foreign risk-free interest rate;

$t=$ the time in years until the expiration of the option;

$\sigma=$ the implied volatility for the underlying exchange rate;

$\Phi=$ the standard normal cumulative distribution function.

Assuming option values at expiration time $E$ to be $C_{E}=\operatorname{Max}\left[0, S_{E}-X\right]$, and $P_{E}=\operatorname{Max}\left[0, X-S_{E}\right]$, options having non-negative prices such as $C, P \geq 0$, upper boundaries $C \leq S, P \leq X$, and lower boundaries

$C \geq \mathrm{e}^{-q t} S-\mathrm{e}^{\left(\hat{i}_{T}\right) t} X$, and $P \geq \mathrm{e}^{\left(\hat{i}_{T}\right) t} X-\mathrm{e}^{-q t} S$, as described by DeRosa [24], as well as Haup [25] and Steland [26], for further details.

\section{First and Higher Order Partial Derivatives}

In terms of the GK-Taylor modified model (GK-T), the new "Greeks" are defined in the following way:

Delta ( $\Delta$ ): $\partial C / \partial S$ and $\partial P / \partial S$ will show the change in the price of a corresponding Call or Put to the change in the price of the underlying asset. Delta is known as the "hedge ratio", since it indicates how much of the underlying asset needs to be bought or sold to hedge the option.

For a Call GK-T, $\partial C / \partial S \equiv \Delta_{c}=\mathrm{e}^{-q t} \Phi\left(d_{1}^{T}\right), 0<\Delta<1$. For a Put GK-T,

$\partial P / \partial S \equiv \Delta_{P}=\mathrm{e}^{-q t}\left[\Phi\left(d_{1}^{T}\right)-1\right]-1<\Delta<0$.

Gamma (Г): It shows the amount that delta $(\Delta)$ changes of $C$ and $P$ when the underlying price changes, in this case $S$, the current spot exchange rate.

For the GK-T Call,

$\partial^{2} \Delta_{C} / \partial S^{2} \equiv \Gamma_{C}=\frac{\Phi\left(d_{1}^{T}\right) \mathrm{e}^{-q t}}{S \sigma \sqrt{t}}, \Gamma_{C}=\Gamma_{P}>0$ For the GKT Put, $\partial \Delta_{P} / \partial S^{2} \equiv \Gamma_{P}=$ as above

Vega $(\boldsymbol{V})$ : Vega is the amount that the theoretical value of an option changes when the volatility $\sigma$ changes by one point (either money or percentage). So,

$V=\partial C / \partial \sigma, \partial P / \partial \sigma$ being $C$ and $P$ the values of a Call option and a Put option.

By deriving, we obtain

$V_{C}=V_{P}=S \mathrm{e}^{-q t} \Phi\left(d_{1}^{T}\right) \sqrt{t}, V_{C}=V_{P}>0$

Theta $(\Theta)$ : Theta represents the loss in value of the option in one time period, all other factors held constant. Then, $\Theta=\partial C / \partial t, \partial P / \partial t$.

By deriving, we obtain the following expressions: 


$$
\begin{aligned}
& \Theta_{C}=-\frac{S \mathrm{e}^{-q t} \Phi\left(d_{1}\right) \sigma}{2 \sqrt{t}}+q S \mathrm{e}^{-q t} \Phi\left(d_{1}^{T}\right)-\hat{i}_{T} X \mathrm{e}^{-\hat{i}_{T} t} \Phi\left(d_{2}^{T}\right), \\
& \Theta_{P}=-\frac{S \mathrm{e}^{-q t} \Phi\left(d_{1}\right) \sigma}{2 \sqrt{t}}-q S \mathrm{e}^{-q t} \Phi\left(d_{1}^{T}\right)+\hat{i}_{T} X \mathrm{e}^{-i t} \Phi\left(d_{2}^{T}\right),
\end{aligned}
$$

Being usually $\Theta_{C}$ and $\Theta_{P}<0$; and $\hat{i}_{T}=\hat{k}_{T}+\hat{m}$.

Rho ( $\rho)$ : We will obtain several "rho" values for the GK-T model, since we have a domestic target interest rate $\hat{i}_{T}$ that depends on $\pi$ and $Y$, and a foreign $q$ interest rate. Rho is the change in the option price when there is a change in the interest rates. They may be critical for this research, since an important outcome of the "blended" IT model will rely on the central bank's ability to operate either open or "shadow" currency options, to stabilize the trend of the exchange rate by minimizing the loss of the inflation target forecasting. Then, rho $\left(\rho_{q}\right)=\frac{\partial C}{\partial q}$ will be the first derivative of the Call option price when there is a change in the foreign risk-free interest rate.

Deriving accordingly, we obtain:

1) For domestic rho, we will derive $\partial C / \partial i$ and $\partial P / \partial i$, as well as in terms of $\pi$ and $Y$, such as $\partial C / \partial \pi, \partial P / \partial \pi$ and $\partial C / \partial Y, \partial P / \partial Y$, so

$$
\begin{aligned}
& \partial C / \partial i \equiv \rho_{C}=X t \mathrm{e}^{-\left(\hat{k}_{T}+\hat{m}\right) t} \Phi\left(d_{2}^{T}\right), \rho_{C}>0 \\
& \partial P / \partial i \equiv \rho_{P}=-X t \mathrm{e}^{-i t} \Phi\left(d_{2}^{T}\right), \rho_{P}<0,
\end{aligned}
$$

Since $\hat{i}_{T}=(1+\varphi) \pi_{T}+\gamma Y_{T}+\hat{m}$, , then

$$
\begin{gathered}
\partial C / \partial \pi=-S(1+\varphi) t \mathrm{e}^{-\left(\hat{k}_{T}+\hat{m}\right) t} \Phi\left(d_{1}^{T}\right), \quad \text { and, } \\
\partial P / \partial \pi=-S(1+\varphi) t \mathrm{e}^{-\left(\hat{k}_{T}+\hat{m}\right) t}\left[1-\Phi\left(d_{1}^{T}\right)\right], \text { while } \\
\partial C / \partial Y=-S \gamma t \mathrm{e}^{-\left((1+\varphi) \pi_{T}+\gamma T_{T}+\hat{m}\right) t} \Phi\left(d_{1}^{T}\right), \quad \text { and, } \\
\partial P / \partial Y=-S \gamma t \mathrm{e}^{-\left((1+\varphi) \pi_{T}+\gamma T_{T}+\hat{m}\right) t} \Phi\left(-d_{1}^{T}\right)
\end{gathered}
$$

2) For foreign rho,

$$
\begin{gathered}
\partial C / \partial q \equiv \rho_{C}=-S t \mathrm{e}^{-q t} \Phi\left(d_{1}^{T}\right), \rho_{C}>0 \\
\partial P / \partial q \equiv \rho_{P}=-S t \mathrm{e}^{-q t} \Phi\left(-d_{1}^{T}\right), \rho_{P}<0
\end{gathered}
$$

Useful higher order partial derivatives for $C$ and $P$, such as Vanna $\left(\partial^{2} V / \partial S \partial \sigma\right)$, Volga $\left(\partial^{2} V / \partial \sigma^{2}\right)$, Speed $\left(\partial^{2} V / \partial \sigma^{2}\right)$, DvegaDtime $\left(\partial^{2} V / \partial \sigma \partial t\right)$, and new "Greeks" (as in Arizmendi [27]), such as DrhoDpi $\left(\partial^{2} C / \partial \pi \partial S ; \partial^{2} P / \partial e \partial S\right)$, and DrhoDoutput $\left(\partial^{2} C / \partial Y \partial S ; \partial^{2} P / \partial Y \partial S\right)$, are also obtained as:

$$
\text { Vanna }=\frac{q}{S}\left[1-\frac{d_{1}^{T}}{\sigma \sqrt{t}}\right],
$$

$$
\begin{aligned}
& \text { Volga }=\frac{q}{\sigma}\left(d_{1}^{T} d_{1}^{T}\right), \\
& \text { Speed }=-\frac{\mathrm{e}^{-\left(\hat{k}_{T}+\hat{m}\right) t} \Phi\left(d_{1}^{T}\right)}{S^{2} \sigma \sqrt{t}}\left[\frac{d_{1}^{T}}{\sigma \sqrt{t}}+1\right],
\end{aligned}
$$

\section{DvegaDtime}

$$
=S \mathrm{e}^{-\left(\hat{k}_{T}+\hat{m}\right) t} \sqrt{t} \Phi\left(d_{1}^{T}\right)\left[\frac{d_{1}^{T} d_{2}^{T}-1}{2 t}-\frac{d_{1}^{T}\left(q-\hat{k}_{T}-\hat{m}\right)}{\sigma \sqrt{t}}-\left(\hat{k}_{T}-\hat{m}\right)\right]
$$

DrhoDpi (Call)

$$
=-(1+\varphi) t \mathrm{e}^{-\left((1+\varphi) \pi_{T}+\gamma Y_{T}+\hat{m}\right) t}\left(\Phi\left(d_{1}^{T}\right)+\frac{\Phi\left(d_{1}^{T}\right)}{\sigma \sqrt{t}}\right),
$$

\section{DrohoDpi (Put)}

$$
=-(1+\varphi) t \mathrm{e}^{-\left((1+\varphi) \pi_{T}+\gamma Y_{T}+\hat{m}\right) t}\left(\Phi\left(-d_{1}^{T}\right)+\frac{\Phi\left(d_{1}^{T}\right)}{\sigma \sqrt{t}}\right) ;
$$

\section{DrhoDoutput (Call)}

$$
=-\gamma t \mathrm{e}^{-\left((1+\varphi) \pi_{T}+\gamma Y_{T}+\hat{m}\right) t}\left(\Phi\left(d_{1}^{T}\right)+\frac{\Phi\left(d_{1}^{T}\right)}{\sigma \sqrt{t}}\right) \text {, and }
$$

\section{DrhoDoutput (Put)}

$$
=\gamma t \mathrm{e}^{-\left((1+\varphi) \pi_{T}+\gamma Y_{T}+\hat{m}\right) t}\left(\Phi\left(-d_{1}^{T}\right)-\frac{\Phi\left(d_{1}^{T}\right)}{\sigma \sqrt{t}}\right)
$$

\section{Conclusion}

This model may be a useful set of tools for central banks and monetary authorities, especially those in countries with a relatively high level of dependency to a foreign currency, mainly through its local financial market and capital inflows. In particular, Call and Put option pricing - even if such derivatives market is not yet developed-may help central banks to intervene in the FX market when a combination of undesirable or untenable interest rate differentials, persistent inflows of capital, or a series of speculative attacks against the foreign currency in the local FX market, may cause the local currency to appreciate beyond certain level, introducing elements of potential instability, precisely opposed to what is sought by using the IT approach. In a free-float to dirty-float spot FX environment, the central bank of any given relatively dollarized country may diminish the cost of some sterilization through open-market-operations by calculating the relative value of its equivalent currency options, corresponding hedging and timely intervention.

\section{Acknowledgements}

The author wants to express its gratitude for the com- 
ments provided by Dominick Salvatore and Erick Rengifo, both at the Department of Economics, Fordham University, as well as Gianfranco Aguirre, Yerson Salcedo and Gabriel Samanez, from GPI Management S.A., that assisted him throughout the process of creating and writing this paper.

\section{REFERENCES}

[1] M. B. Garman and S. W. Kohlhagen, "Foreign Currency Options Values," Journal of International Money and Finance, Vol. 2, No. 3, 1983, pp. 231-237.

[2] R. J. Caballero, "Macroeconomics after the Crisis: Time to Deal with the Pretense-of-Knowlegde Syndrome," Journal of Economic Perspectives, Vol. 24, No. 4, 2010, pp. 85-102. doi:10.1257/jep.24.4.85

[3] M. Goodfriend, "How the World Achieved Consensus on Monetary Policy," Journal of Economic Perspectives, Vol. 21, No. 4, 2007, pp. 47-68. doi:10.1257/jep.21.4.47

[4] J. B. Taylor, "The Effectiveness of Central Bank Independence versus Policy Rules," American Economic Association Annual Meeting San Diego, California, January 2013, 22 p.

[5] J. B. Taylor, "Monetary Policy Rules Works and Discretion Doesn't: A Tale of Two Eras," Journal of Money, Credit and Banking, Vol. 44, No. 6, 2012, pp. 1017-1032. doi:10.1111/j.1538-4616.2012.00521.x

[6] M. Woodford, "The Case for Forecast Targeting as a Monetary Policy Strategy," Journal of Economic Perspectives, Vol. 21, No. 4, 2007, pp. 3-24.

doi:10.1257/jep. 21.4 .3

[7] J. Ostry, A. R. Ghosh and M. Chamon, "Two Targets, Two Instruments: Monetary and Exchange Rate Policies in Emerging Market Economies," IMF Staff Discussion Note, 29 February 2012, SDN/12/01.

[8] N. Apergis, S. M. Miller, A. Panethimitakis and A. Vamvakidis, "Inflation Targeting and Output Growth: Evidence from Aggregate European Data," University of Connecticut, Department of Economics, Working Paper Series No. 2005-06, 2005.

[9] D. Salvatore, "Exchange Rate Misalignments and the Present International Monetary System," Journal of Policy Modeling, Vol. 34, No. 4, 2012, pp. 594-604. doi:10.1016/j.jpolmod.2012.05.008

[10] D. Salvatore, J. W. Dean and T. D. Willett, "The Dollarization Debate," Oxford University Press, Oxford, 2003. doi:10.1093/0195155351.001.0001

[11] E. Ozsoz, E. W. Rengifo and D. Salvatore, "Dollarization as an Investment Signal in Developing Countries: The Case of Croatia, Czech Republic, Peru, Slovak Republic and Turkey," Fordham University, Discussion Paper No. 2008-16, 2008.

[12] D. Veestraeten, "Currency Option Pricing in a Credible Exchange Rate Target Zone," University of Amsterdam,
2012.

[13] D. Archer, "Foreign Exchange Market Intervention: Methods and Tactics," Foreign Exchange Market Intervention in Emerging Markets: Motives, Techniques and Implications, BIS Papers No. 24, May 2005.

[14] M. del Rosario Bernedo and J. M. Azañero, "La Banca Central y los Derivados Financieros: El caso de las Opciones de Divisas," Banco Central de Reserva del Perú, Estudios Económicos, 2003, pp. 113-148.

[15] P. Breuer, "Central Bank Participation in Currency Options Markets," International Monetary Fund, Working Paper WP/99/140, 1999.

[16] G. Keles and T. S. Öncü, "Alternative Tools of Trade for Central Banks and Other Financial Institutions: Foreign Exchange Liquidity Options," IFC Bulletin No. 31, 2009, pp. 181-196.

[17] O. Mandeng, "Central Bank Foreign Exchange Market Intervention and Option Contract Specification: The Case of Colombia," International Monetary Fund, Working Paper WP/03/15, 2003.

[18] V. Orellana and P. Rodríguez, "Methodology for Measuring Derivatives at the Central Bank of Chile," IFC Bulletin, No. 31, 2009, pp. 165-180.

[19] S. H. Lee and A. G. Malliaris, "Currency Markets and International Interest Rate Parity," In: K. Baker and L. Riddick, Eds., Survey of International Finance, Oxford University Press, Oxford, 2011

[20] J. B. Taylor, "The Role of the Exchange Rate in Monetary-Policy Rules," American Economic Review, Vol. 91, No. 2, 2001, pp. 263-267. doi:10.1257/aer.91.2.263

[21] J. Uribe and J. Toro, "Foreign Exchange Market Intervention in Colombia," Foreign Exchange Market Intervention in Emerging Markets: Motives, Techniques and Implications, BIS Papers No. 24, May 2005.

[22] J. B. Taylor, "Discretion versus Policy Rules in Practice," Carnegie-Rochester Conference Series on Public Policy, Vol. 39, No. 1, 1993, pp. 195-214. doi:10.1016/0167-2231(93)90009-L

[23] T. Molodtsova and D. Papell, "Taylor Rule Exchange Rate Forecasting during The Financial Crisis," Working Paper 18330, National Bureau of Economic Research, 2012.

[24] D. F. DeRosa, "Options on Foreign Exchange," 3rd Edition, Wiley Finance, Hoboken, 2008.

[25] E. G. Haug, "The Complete Guide to Option Pricing Formulas," McGraw-Hill, New York, 2007.

[26] A. Steland, "Financial Statistics and Mathematical Finance. Methods, Models and Applications," John Willey \& Sons, Ltd., Hoboken, 2012. doi:10.1002/9781118316443

[27] L.-F. Arizmendi, “Open and Shadow Currency Options as Policy Tool for Central Banks with Inflation Targeting and Dollarized Economies: The Case for Peru," Fordham University, Internal Discussion Paper, January 2013. 